3

$$
\text { Conf rinmsis } 54
$$

\title{
Measurement of the Elastic Modulus of Kapton Perpendicular to the Plane of the Film at Room and Cryogenic Temperatures
}

\author{
M. Davidson, S. Bastian and F. Markley \\ Fermi National Accelerator Laboratory \\ P.O. Box 500, Batavia, Illinois 60510
}

April 1992

Presented at the Fourth Annual IISSC Conference, New Orleans, LA, March 4-6, 1992. 


\section{Disclaimer}

This report was prepared as an account of work sponsored by an agency of the United States Government. Neither the United States Government nor any agency thereof, nor any of their employees, makes any warranty, express or implied, or assumes any legal liability or responsibility for the accuracy, completeness, or usefulness of any information, apparatus, product, or process disclosed, or represents that its use would not infringe privately owned rights. Reference herein to any specific commercial product, process, or service by trade name, trademark, manufacturer, or otherwise, does not necessarily constitute or imply its endorsement, recommendation, or favoring by the United States Government or any agency thereof. The views and opinions of authors expressed herein do not necessarily state. or reflect those of the United States Government or any agency thereof. 


\title{
MEASUREMENT OF THE ELASTIC MODULUS OF KAPTON PERPENDICULAR TO THE PLANE OF THE FILM AT ROOM AND CRYOGENIC TEMPERATURES
}

\author{
Mark Davidson, Steve Bastian and Finley Markley \\ Fermi National Accelerator Laboratory* \\ P. O. Box 500 \\ Batavia, IL 60510
}

\begin{abstract}
Understanding the short term elastic properties, (i.e. the instantaneous modulus) of Kapton is essential in determining the loss of prestress during storage and operation of SSC dipole magnets. The magnet prestress contributes directly to the coil response to the Lorentz forces during ramping. The instantaneous modulus is important in extrapolating short term stress relaxation data to longer times. Most theoretical fits assume a time independent component and a time dependent (:mmponent. The former may be represented by the Kapton modulus near zero $K$ where all relaxation processes have been 'frozen' out. ${ }^{1}$ Modulus mea'surements at $77 \mathrm{~K}$ and $4.2 \mathrm{~K}$ may point to a correct value for the near zero $\mathrm{K}$ modulus. Three companion papers presented at this conference will be: 1) "Stress Relaxation in SSC $50 \mathrm{~mm}$ Dipole Coils" 2) "Temperature Dependence of the Viscoelastic Properties of SSC Coil Insulation (Kapton)" 3) "Theoretical Methods for Creep and Stress Relaxation Studies of SSC Coil."
\end{abstract}

\section{INTRODUCTION}

Kapton is the primary insulator in SSC dipole magnets. The understanding of the material properties of Kapton is crucial in determining the loss of prestress in the collared coils. A general equation for creep (or stress relaxation which has the same general format, see companion paper 3 , for further details on creep equations) is:

$$
E=E_{0}+E_{1} t^{n}
$$

This equation describes the time dependency of creep (stress held constant and strain varied) and stress relaxation (strain held constant and stress is allowed to vary). This equation has several constants that can be determined

* Operated by Universities Research Association, Inc., for the U.S. Department of Energy. 
experimentally. The $E_{0}$ in Equation 1 is the modulus at time $t=0$, and can be called the time independent modulus. The $E_{1} t^{n}$ term is the time dependent modulus. $E_{0}$ may be determined experimentally by finding a way to eliminate the effects of time. There are a couple of ways this can be attempted. One would be to measure a modulus by loading a piece of Kapton film in tension as fast as possible while taking stress strain data. 2 The other method (this author's method of choice) was to find the modulus at several temperatures close to $0 \mathrm{~K}$ (although $\mathrm{Du}$ Pont hes low temperature modulus data, this was done in tension and not in complession) and this along with data collected at other temperatures was used to find modulus as a function of temperature and the modulus extrapolated to near $0 \mathrm{~K}$. This $0 \mathrm{~K}$ modulus could be synonymous with the instantaneous modulus. This is because the modulus at this temperature has no time dependent portion, i.e., the time dependence of the modulus is 'frozen' out at $0 \mathrm{~K}$. In normal modulus measurements, while a material is being stressed it is also creeping. The slower the material is stressed the more time it has to creep; the faster it is stressed the less time it has to creep, therefore, the faster the stress rate the less creep will show up in the modulus measurements and vice versa. The freezing out principle attempts to eliminate this recovery while stressing at a rate that is not considered 'fast'.

\section{TEST MATERIALS AND PROCEDURES}

The Kapton samples used were two stacks of $10012.7 \mathrm{~mm}$ squares of $0.127 \mathrm{~mm}$ film (stacks R1 and L2). This film was used because it is similar to the film used in the actual coils ( $0.0254 \mathrm{~mm}$ film was used in the actual coil. We used $0.127 \mathrm{~mm}$ film because less were needed to make the stack). The stacked configuration was utilized because taking stress strain measurements perpendicular to the plane of a single piece of $0.127 \mathrm{~mm}$ film is very difficult at best. Although Kapton is ava: able in a solid form (Vespel) this was not used due to the manufacturing techuiques of Vespel. Because of these techniques Vespel's macro structure is dilferent from the Kapton and it's material properties would not be representative of the film. The tests were done perpendicular to the plane of the film because this is how the stresses are applied to the Kapton in an actual coil.

A $\pm 3.81 \mathrm{~mm}$ MTS Corporation extensometer calibrated at 300,77 and 4.2 $\mathrm{K}$ was used to measure the displacement of the stack during loading. The extensometer was designed by MTS to operate in a liquid nitrogen environment, but we calibrated it for use in liquid helium. (It was calibrated in an apparatus designed by J. Mashek). See Figure 1.

A specific fixture was designed to hold the Kapton stack during loading. The walls of this fixture were spring loaded to allow for the expansion of the stack perpendicular to the applied force to avoid measurement of the bulk modulus. The fixture also had a guided loading ram, allowing forces to be applied to the stack without slipping of the ram (see Figure 2).

The sample was tested on two testing machines. The first being the Instron 8500 servohydraulic testing machine, $\varepsilon$. fully automated computer operated servo driven testing machine. This mechine was used to measure the stack height of the Kapton (as explained in the next section). The second machine was the Low Temperature Loader (LTL), an apparatus that was designed within Fermilab for cryogenic materials testing. The machine 


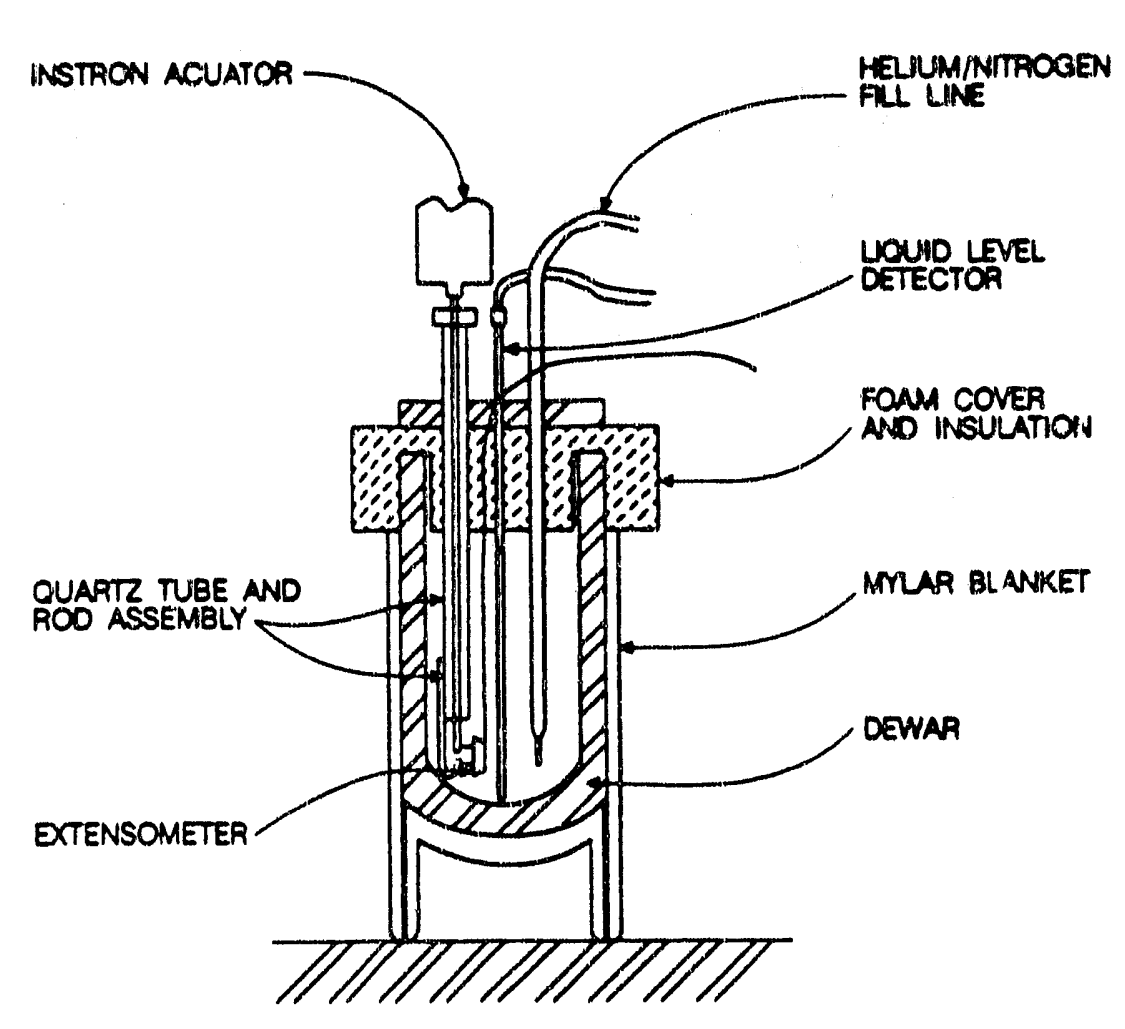

Figure 1. Extensometer Calibrator

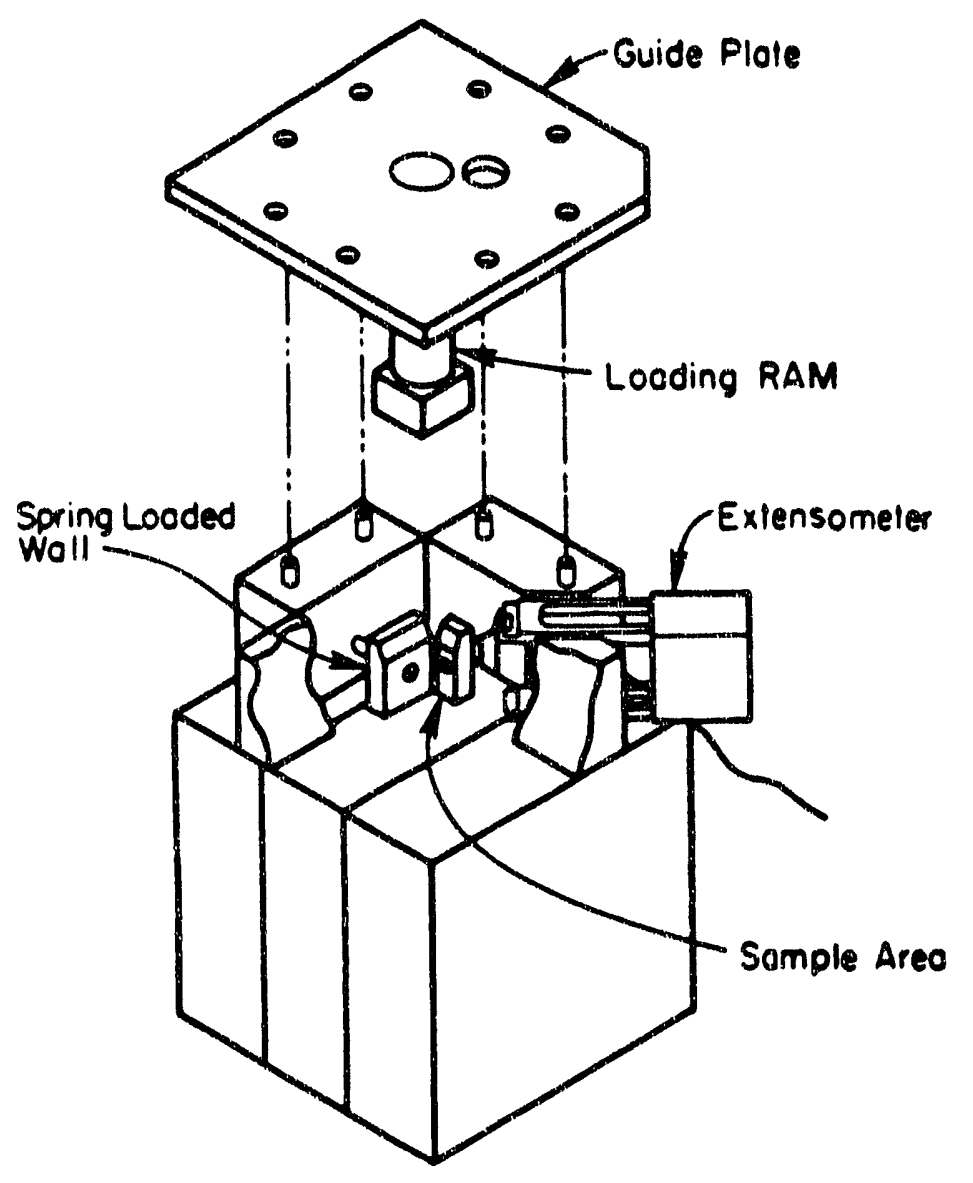

Figure 2. Test Fixture 
consists of a G-10 tube within a G-10 tube. The inner tube has two steel plates shrink fitted to the end and applies the load to the sample, while the outer tube also has shrink fitted rings on the end. A steel plate is bolted to this ring where the sample sits during loading. This design is patented and licensed for use by the Instron Corporation (see Figure 3). The LTL can be fitted with a dewar that covers the sample area and allows for testirg with liquid nitrogen or helium. The press is also fitted with a $90 \mathrm{kN}$ load cell for measuring applied forces.

The force data as well as the output from the extensometer were collected on an IBM compatible PC via an HP3457A digital multimeter. An HP6227B dual voltage source was used to power the extensometer as well as the load cell.

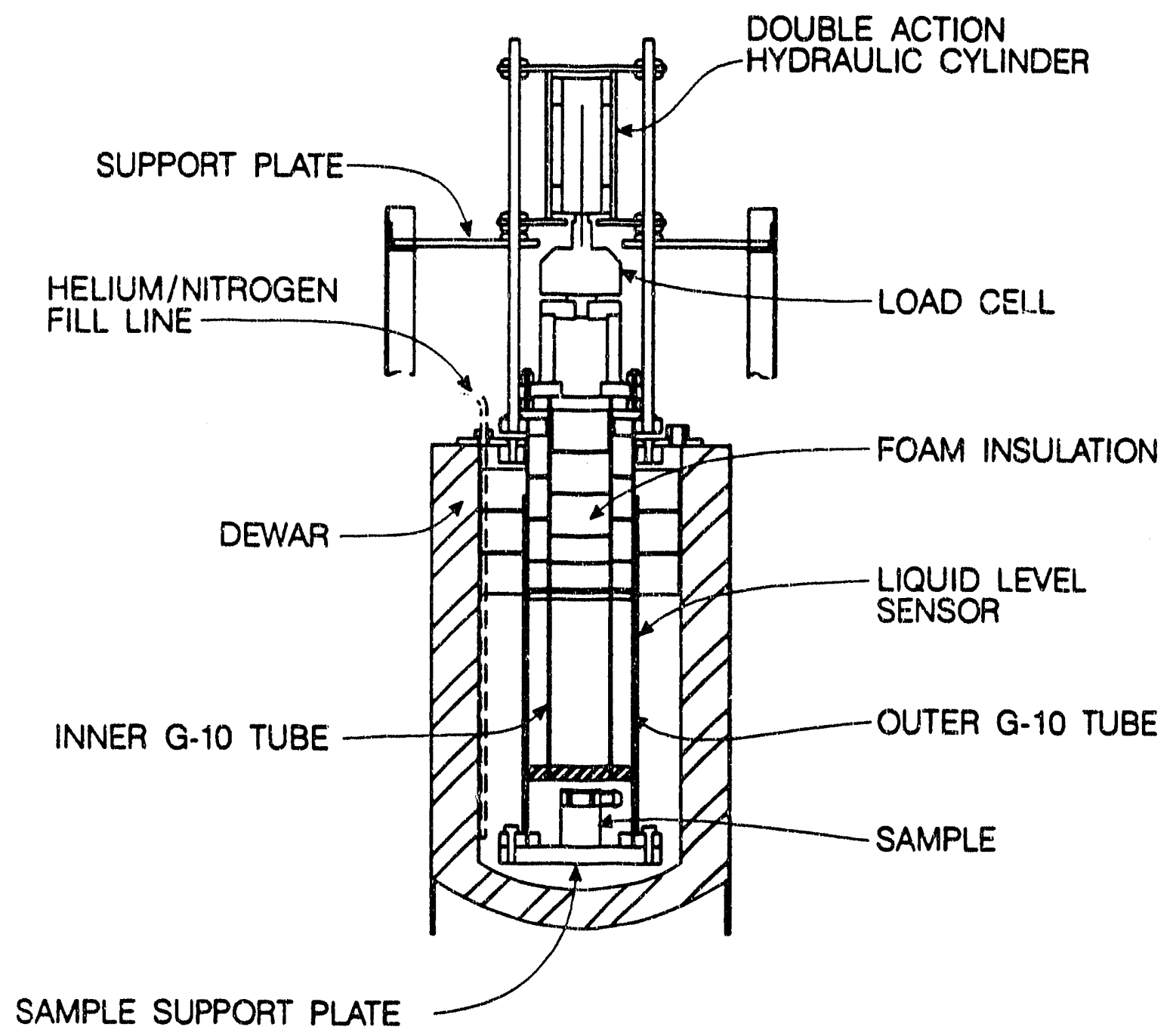

Figure 3. Low Temperature Loader 


\section{TESTING OF THE RAPION STACKS}

\section{Stack height measurements}

Measuring the height of the stack proved difficult because of the slight inconsistencies in thickness so careful steps were taken to measure the stack height. The stack of Kapton was dried before the test by storing it in an oven with silica gel desiccant (to absorb any moisture) at $400 \mathrm{~K}$. Kapton is very absorbent in regard to water; about $3 \%$ water at $100 \%$ relative humidity. The extensometer was then mounted to the fixtura and connected to the HP voltage supply at seven volts excitation. A $12.7 \mathrm{~mm}$ cube of steel was then placed into the testing fixture in place of the Kapton stack to serve as a calibration block for stack height measurements. A reading of the extensometer position was then taken at the $12.7 \mathrm{~mm}$ point. The actual stack of Kapton was then placed in the fixture and load displacement data was taken up to $4.5 \mathrm{kN}$. The stack height was then calculated by fitting the straight portion of this data to a linear equation and extrapolating to zera load. This point was taken as the top of the stack.

The stack height was also found using two other methods: weighing the stack then using the density of Kapton from Du Pont data to calculate the stack height, and measuring individual pieces of Kapton with a micrometer. An average of the three methods was used as the actual stack height (see Table 1 for further details).

\section{Measurement of the Elastic Modulus}

The measurement of the elastic modulus was done in the same manner as the stack height measurements. The only exception was that the test was done on the LTL. The linear portion of the force displacement curve was fitted to a straight line equation, and the slope of the straight line was then converted to modulus. This was done at 300,77 and $4.2 \mathrm{~K}$. The modulus data was then graphed vs. temperature (note that this included the modulus from data provided by Du Pont; see Table 2). We attempted to fit the data with a cubic, $\log -\log$, modulus proportional to $1 / \mathrm{T}$ and a $\log E$ curve. The best fit was found by taking the log of the temperature and doing a linear regression to the data which had an $R$ (correlation coefficient) of 0.97 which was the best of all the fits (see Figure 4 and Equation 2).

Table 1. Stack Height Measurements

(millimeters)

\begin{tabular}{lcc}
\hline & $\mathrm{R} 1$ & $\mathrm{~L} 2$ \\
Density & 12.645 & 12.415 \\
Micrometer & 12.985 & 12.425 \\
Loading & 12.187 & 12.688 \\
Mean & 12.606 & 12.509 \\
\hline
\end{tabular}


Table 2. Modulus Measurements

(Mega Pascals)

\begin{tabular}{llll}
\hline & $300 \mathrm{~K}$ & $77 \mathrm{~K}$ & $4.2 \mathrm{~K}$ \\
Du Pont * & 2966 & 3517 & 5517 \\
L2 & 2276 & 3310 & 4483 \\
R1 & 2345 & 3379 & 5103 \\
\hline
\end{tabular}

*(As expected, the Du Pont Moduli are higher than $\mathrm{L} 2$ and $\mathrm{R} 1$ because Du Pont tests are done in tension, i.e. the direction of the molecular orientation of the film.)

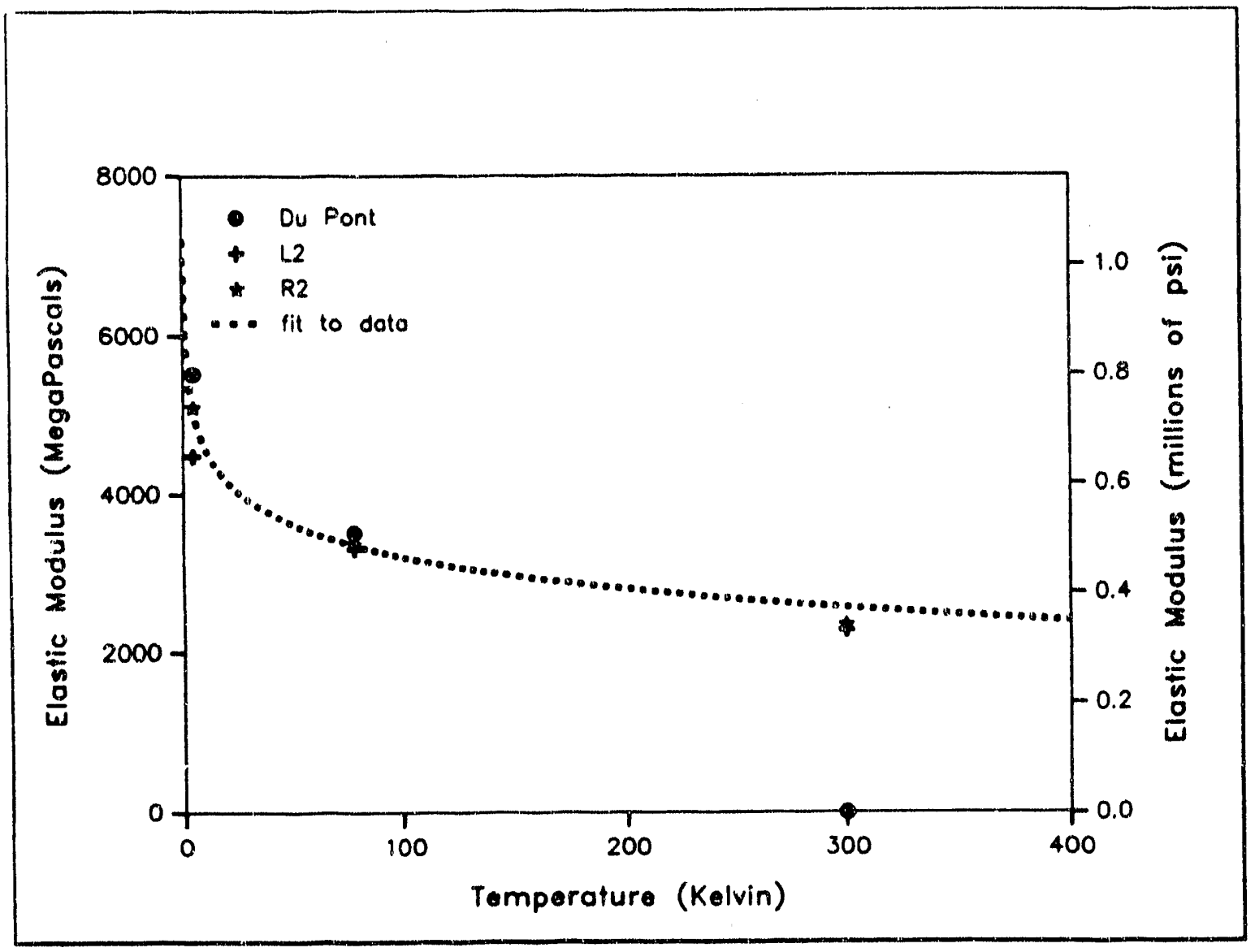

Figure 4. Elastic Modulus of Kapton 


$$
\begin{aligned}
& E=k \log T+E_{O} \\
& k=-1337 \\
& E_{O}=5879
\end{aligned}
$$

\section{CONCLUSIONS}

Equation $z$ implies as $\mathrm{T}$ goes to $0, E$ goes to infinity, therefore a clear zero $\mathrm{K}$ modulus for Kapton cannot be determined from Equation 2. This follows the reasoning that at zero $\mathrm{K}$ there is no molecular motion, but by definition modulus requires there be motion. The infinite modulus agrees with the value found for the reciprocal of the instantaneous creep compliance (companion paper 2). In the future stress relaxation and creep data will also be analyzed with mathematical models that do not assume a time independent component.

\section{REFERENCES}

1. Caufield, Edward M., "An Investigation of Stress Temperature, and Time Dependent Strains in a Randomly Oriented Fiber Reinforced Composite with Special Emphasis Given to Thermal Stress Situations," Ph.D. Thesis, University of Illinois, Department of Theoretical and Applied Mechanics, 1979.

2. Michaeli, W., Folster, Th., Lewen, B., and Aachen, "Simulating the Long-Term Behaviour of Plastics," 1989.

3. Du Pont Chemicals "Cryogenic Properties of Kapton Polymide Film." 

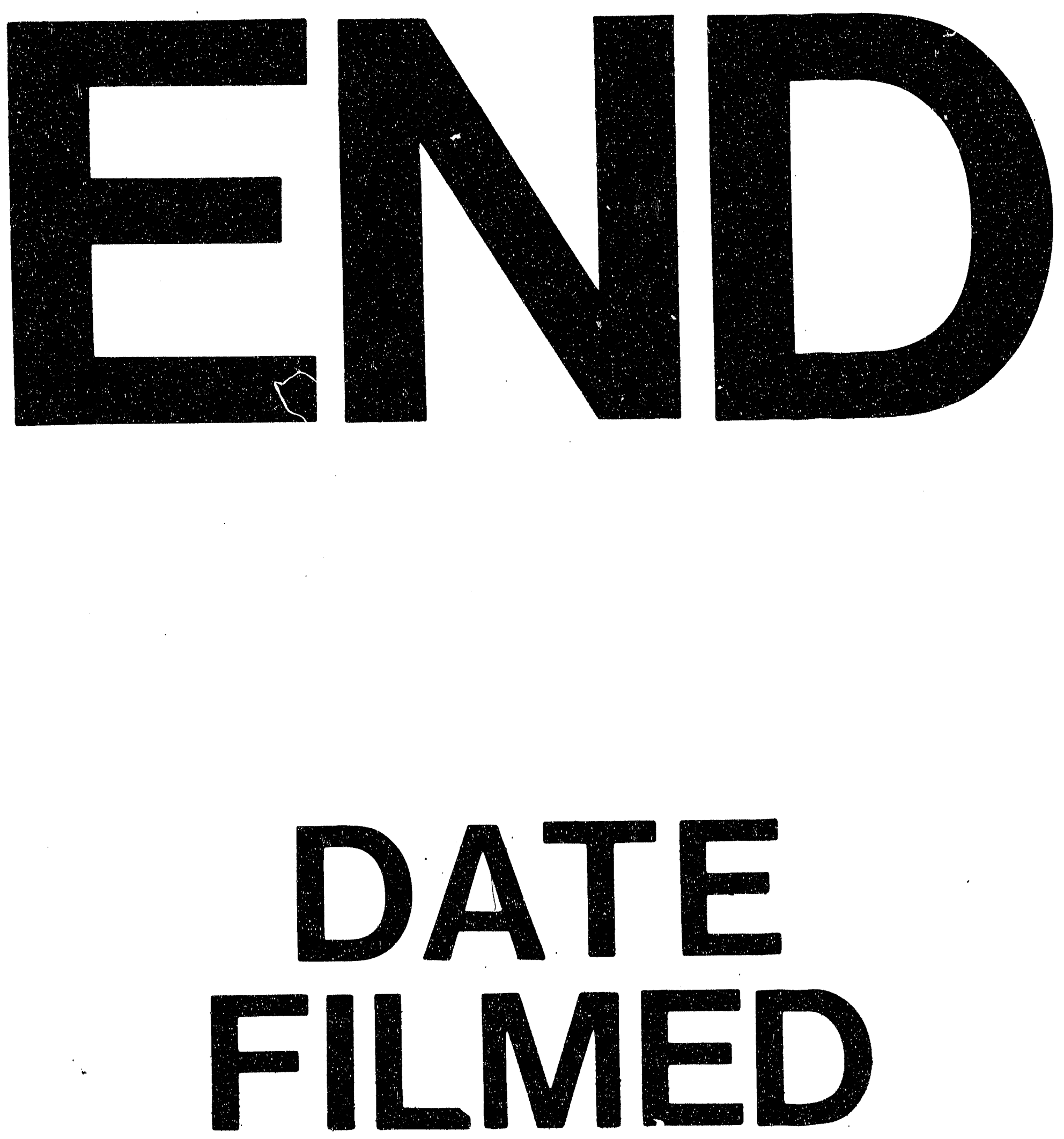

1

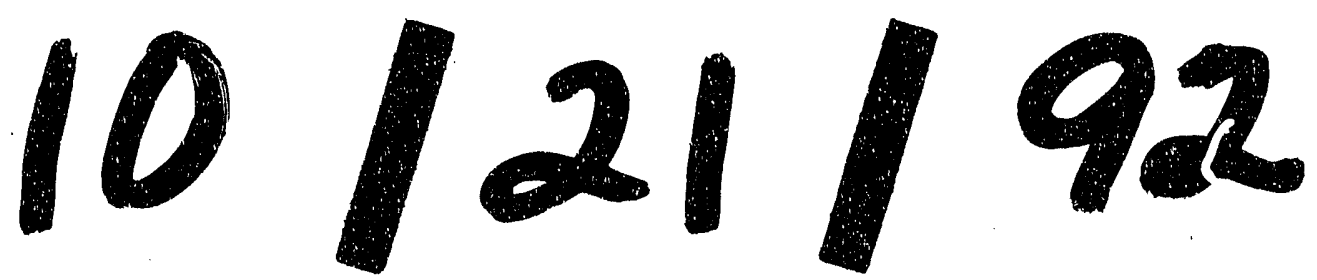


